\title{
Strategi Perancangan Sekolah Alam Smk Pertanian Dengan Pendekatan Sistem Permakultur Di Purbalingga
}

\author{
Yusak Hartanto Gondo, Hardiyati, Kusumaningdyah Nurul Handayani \\ Program Studi Arsitektur \\ Fakultas Teknik \\ Universitas Sebelas Maret \\ Email : yusak.gondo@gmail.com
}

\begin{abstract}
Despite its potentials to be developed as a farming district, Purbalingga faces numerous land reforms and decline of workforce in agriculture field. It also lacks proper agricultural education institution. This design proposal aims to solve the problems. Agriculture Vocational High School, applying Permaculture System in Purbalingga offers four focus programs: agriculture, livestock farming, fishery, and food technology. The school is not only providing education for the students, but also for the local farmers and entrepreneurs of the fiels. The applied permaculture approach asks for five principles (deduced from the fourteen original principles) to be fulfilled: integrated location, biological source, humanly scale, energy cycle, and power-source planning.
\end{abstract}

Keywords: vocational high school, agriculture, permaculture, purbalingga.

\section{LATAR BELAKANG}

\subsection{Purbalingga Kota Pertanian}

Purbalingga merupakan kabupaten di Provinsi Jawa Tengah yang memiliki potensi pertanian berupa lahan subur; dengan tiga sungai besar, dan 14 sungai kecil sebagai sumber air. Sebanyak 70,49\% lahan di Purbalingga adalah lahan pertanian yang menghasilkan mencapai surplus beras sebanyak 45.000 ton pada 2013, 23.000 ton pada 2014, dan 64.000 ton pada 2015 (Purbalingga Dalam Angka, 2015).

Namun, pertanian di Purbalingga juga memiliki tantangan dan ancaman seperti rendahnya jumlah petani - hanya sebesar 30,51\% (Purbalingga Dalam Angka, 2015); minimnya tingkat regenerasi petani karena generasi muda lebih memilih bekerja di pabrik bahkan saat baru lulus SMP; dan ancaman alih fungsi lahan pertanian menjadi lahan industri dan perumahan. Selain itu, di Purbalingga hanya ada satu SMK dengan prodi pertanian. Oleh karena itu, berdasarkan fenomena di atas, maka urgensi dalam proses desain adalah perancangan SMK dengan mengolah potensi alam (pertanian) secara maksimal melalui pendekatan sistem permakultur.

\subsection{Permasalahan Desain}

Permasalahan yang ditemukan dalam proses desain adalah:

1. Mengintegrasikan bangunan dengan alam disekitarnya

2. Elemen arsitektural untuk mewadahi proses pembelajaran yang kondusif

3. Penggunaan Energi Independen pada bangunan

\subsection{Metode Desain}

Berikut adalah penyelesaian permasalahan yang muncul dalam proses desain, yang diselesaikan melalui pendekatan sistem permakultur.

1. Mengintegrasikan bangunan dengan alam, dan diselesaikan melalui zonasi.

2. Elemen arsitektural yang dapat mewadahi proses pembelajaran yang kondusif, akan diselesaikan melaui pemilihan massa awal dan gubahan massa, serta penggunaan material lokal pada tampilan bangunan.

3. Penggunaan energi independen pada bangunan yang diwujudkan melalui perancangan sistem utilitas yang mengambil dari alam serta mengembalikan ke alam melalui perancangan ramah lingkungan, serta perancangan sumber energi listrik yang menggunakan energi alam dengan cara mengolahnya sendiri. 


\subsection{Studi Literatur}

\subsubsection{Permakultur}

\subsubsection{Definisi Permakultur}

Permakultur merupakan sistem yang diadaptasi sehingga menyerupai ekosistem alami, yang bersifat regeneratif dan mampu melestarikan diri sendiri (Paulus Mintarga \& Kusumaningdyah N. H. Satu Proses Merajut Asa Dari Yang Sisa- Belajar Dari Alam Dan Ibu Bumi, 2014). Berikut adalah beberapa definisi permakultur menurut para ahli:

1. Dalam sejarahnya, penerapan permakultur sudah ada sejak tahun 1929 yaitu pada penanaman pohon, seperti tanaman kacang dan pohon buah yang ditanam dalam satu lahan, dimana keduanya saling menguntungkan satu sama lain, tidak hanya bagi tanamannya, tetapi juga bagi petani yang menanamnya (John Russel, Tree Crops: a Permanent Agriculture, 1929).

2. Permakultur merupakan sebuah sistem yang terintegrasi tidak hanya meliputi agrikultur, holtikultur, arsitektur, dan ekologi tetapi juga mencakup sistem ekonomi, strategi akses lahan, dan sistem legal untuk bisnis dan komunitas (Bill Mollison, Permaculture One, 1978).

3. Permakultur membantu kita memahami dan menciptakan integrasi yang harmonis antara alam dan manusia dengan cara-cara yang harmonis. (Lachlan McKenzie, Panduan untuk Permakultur, Menuju Hidup Lestari, 2006).

Dari ketiga buku tersebut akan dibandingkan dalam hal relevansi dan kelengkapan pembahasan untuk menemukan teori yang akan dipakai dalam proses perencanaan dan perancangan (tabel 1).

Tabel 1. Perbandingan Teori Permakultur

\begin{tabular}{|c|c|c|c|c|}
\hline \multicolumn{2}{|r|}{ PEMBANDING } & $\begin{array}{c}\text { John } \\
\text { Russel }\end{array}$ & $\begin{array}{c}\text { Bill } \\
\text { Mollison }\end{array}$ & $\begin{array}{l}\text { Lachlan } \\
\text { McKenzie }\end{array}$ \\
\hline \multirow{10}{*}{ 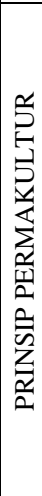 } & Efek Tepian & $X$ & $X$ & $\mathrm{O}$ \\
\hline & $\begin{array}{l}\text { Perencanaan } \\
\text { Energi }\end{array}$ & $\mathrm{X}$ & $\mathrm{O}$ & $\mathrm{O}$ \\
\hline & $\begin{array}{l}\text { Tanggung Jawab } \\
\text { Individu }\end{array}$ & $\mathrm{X}$ & X & $\mathrm{O}$ \\
\hline & Unsur Ganda & $\mathrm{O}$ & $\mathrm{O}$ & $\mathrm{O}$ \\
\hline & Pengamatan & $\mathrm{O}$ & $\mathrm{O}$ & $\mathrm{O}$ \\
\hline & Siklus Energi & $\mathrm{X}$ & $\mathrm{X}$ & $\mathrm{O}$ \\
\hline & $\begin{array}{l}\text { Melihat } \\
\text { Solusinya, Bukan } \\
\text { Masalahnya }\end{array}$ & $\mathrm{O}$ & X & $\mathrm{O}$ \\
\hline & Fungsi Ganda & $\mathrm{O}$ & $\mathrm{O}$ & $\mathrm{O}$ \\
\hline & $\begin{array}{l}\text { Bekerjasama, } \\
\text { Bukan Bersaing }\end{array}$ & $\mathrm{O}$ & $\mathrm{X}$ & $\mathrm{O}$ \\
\hline & Skala & $X$ & $\mathrm{O}$ & $\mathrm{O}$ \\
\hline
\end{tabular}

\begin{tabular}{|l|l|c|c|c|}
\hline & $\begin{array}{l}\text { Sumber-sumber } \\
\text { Biologi }\end{array}$ & $\mathrm{O}$ & $\mathrm{O}$ & $\mathrm{O}$ \\
\cline { 2 - 4 } & Rangkaian Alami & $\mathrm{O}$ & $\mathrm{O}$ & $\mathrm{O}$ \\
\cline { 2 - 4 } & Perbedaan & $\mathrm{O}$ & $\mathrm{O}$ & $\mathrm{O}$ \\
\hline $\begin{array}{l}\text { Lokasi } \\
\text { Berhubungan }\end{array}$ & $\mathrm{X}$ & $\mathrm{O}$ & $\mathrm{O}$ \\
\hline Tahun Terbit & 1929 & 1978 & 2006 \\
\hline $\begin{array}{l}\text { Relevansi } \\
\text { (Lokasi Penelitian } \\
\text { Dilakukan) }\end{array}$ & $\mathrm{US}$ & Australia & $\begin{array}{c}\text { Timor } \\
\text { Leste }\end{array}$ \\
\hline
\end{tabular}

(Gondo, 2016)

Berdasarkan tabel diatas (tabel 1), dapat diketahui bahwa melalui kelengkapan prinsip serta relevansinya berdasarkan waktu dan lokasi penelitian sebagai acuan dalam perbandingan antara ketiga teori, maka dapat disimpulkan bahwa teori milik McKenzie paling sesuai digunakan sebagai landasan dalam proses perancangan, sehingga teori yang akan digunakan dalam proses perencanaan dan perancangan adalah teori permakultur Lachlan McKenzie dalam bukunya "Panduan untuk Permakultur, Menuju Hidup Lestari".

1.4.1.1. Prinsip Permakultur

Tabel 2. Pengelompokkan Prinsip Permakultur

\begin{tabular}{|c|c|}
\hline PRINSIP PERMAKULTUR & PRINSIP UTAMA \\
\hline Efek Tepian & \multirow{3}{*}{ Perencanaan Energi } \\
\hline Perencanaan Energi & \\
\hline Tanggung Jawab Individu & \\
\hline Unsur Ganda & \multirow{5}{*}{ Siklus Energi } \\
\hline Pengamatan & \\
\hline Siklus Energi & \\
\hline $\begin{array}{l}\text { Melihat Solusinya, Bukan } \\
\text { Masalahnya }\end{array}$ & \\
\hline Fungsi Ganda & \\
\hline $\begin{array}{l}\text { Bekerjasama, Bukan } \\
\text { Bersaing }\end{array}$ & \multirow[t]{2}{*}{ Skala } \\
\hline Skala & \\
\hline Sumber-sumber Biologi & \multirow{2}{*}{ Sumber-sumber Biologi } \\
\hline Rangkaian Alami & \\
\hline Perbedaan & \multirow{2}{*}{ Lokasi Berhubungan } \\
\hline Lokasi Berhubungan & \\
\hline
\end{tabular}

(McKenzie, 2006)

Permakultur memiliki empat belas prinsip yang menjadi pedoman dan intisari, dari keempat belas prinsip tersebut, beberapa memiliki kesamaan sehingga dapat dikelompokkan menjadi lima poin utama, dimana prinsip yang lain telah termasuk dalam lima prinsip tersebut (tabel 2), dan kelima prinsip tersebut menjadi dasar dalam proses perancangan dan diaplikasikan kedalam masing-masing analisis.

1. Lokasi berhubungan (menempatkan setiap unsur yang saling berhubungan agar saling 
menguntungkan), akan diaplikasikan pada analisis zonasi.

2. Sumber-sumber biologi (bekerjasama dengan alam melalui penggunaan bahanbahan yang ada di alam), akan diaplikasikan pada analisis tampilan dan struktur.

3. Skala (menciptakan sistem skala kemanusiaan melalui desain yang sederhana dan sesuai), akan diaplikasikan pada bentuk dan gubahan massa.

4. Siklus energi (dalam sistem alami tidak ada limbah atau polusi, sisa dari suatu proses akan menjadi sumber untuk proses lainnya), akan diaplikasikan pada analisis sistem utilitas, dimana grey water dan black water diolah sehingga dapat dipakai kembali untuk keperluan lainya, kemudian mengolah air hujan dan air sungai untuk dimanfaatkan dalam kebutuhan sehari-hari.

5. Perencanaan energi (memanfaatkan energi dan sumber-sumber yang ada untuk menghemat energi), akan diaplikasikan pada analisis sumber energi listrik, dimana perencanaan dan perancangan energi listrik akan memanfaatkan energi dan sumbersumber yang ada di sekitar tapak.

\subsubsection{Sekolah Alam, Green School, Rumah Oli}

\subsubsection{Tentang Sekolah Alam}

Sekolah Alam adalah sekolah dengan konsep pendidikan berbasis alam semesta (Maryati, 2007), yaitu menggunakan segala sesuatu yang ada disekitarnya sebagai materi pembelajaran. Sekolah alam juga merupakan pendidikan alternatif yang menggunakan alam sebagai media utama pembelajaran sehingga, siswa belajar lebih banyak di alam terbuka (Djuwita dalam Virrayani, 2014).

\subsubsection{Green School}

Sekolah alam bertaraf internasional ini didirikan pada tahun 2007 oleh John Hardy, seorang pembuat perhiasan yang tergerak untuk peduli terhadap kerusakan lingkungan yang sudah cukup gawat. John mencoba menyumbangkan dan memecahkan masalah lingkungan ini dengan cara mendirikan Green School di Bali. Visi Green School ini adalah mendidik anak-anak di sekolah ini supaya lebih mencintai lingkungan dan agar saat mereka dewasa dapat memberikan dampak bagi pemeliharaan bumi.
Bangunan yang ada di Green School menggunakan bambu sebagai material utamanya, dan alang-alang sebagai penutup atapnya. Material bambu yang juga digunakan sebagai struktur ini dianggap berkarakter luwes dan artistik dalam mengikuti alur maupun bentuk arsitektur.

\subsubsection{Rumah Oli (Ocean of Life Indonesia)}

Ocean of Life Indonesia adalah sebuah komunitas yang terdiri dari pecinta lingkungan yang memfokuskan kegiatannya pada pendidikan lingkungan, pertanian yang berkelanjutan, dan pengembangan masyarakat. Ocean of Life berkomitmen untuk mendorong dan mendukung upaya pemeliharaan dan penjagaan kelestarian lingkungan dengan melibatkan komunitas masyarakat didalamya.

Bentuk nyata aplikasi dari visi mereka adalah dengan menerapkan sistem-sistem seperti penyaringan air hujan, pengolahan dan pemaikan kembali grey water, serta pengolahan black water yang digunakan sebagai sumber energi listrik, gas untuk memasak, serta pupuk alami yang baik bagi tanaman pada bangunan yang disebut Rumah OLI ini.

\section{PURBALINGGA}

\subsection{Lokasi}

apak terpilih berada di Desa Bukateja, Kec. Bukateja, Kab. Purbalingga (gambar 1).

Desa Bukateja memiliki lahan pertanian yang luasnya lebih dari setengah luas wilayah desa, selain itu juga terdapat dua komunitas yang berfokus pada pengembangan pertanian di Desa Bukateja (kelompok tani Gemah Ripah dan Forum Pemuda Bukateja Bersatu), sehingga Desa Bukateja sesuai untuk dijadikan sebagai lokasi perancangan. 


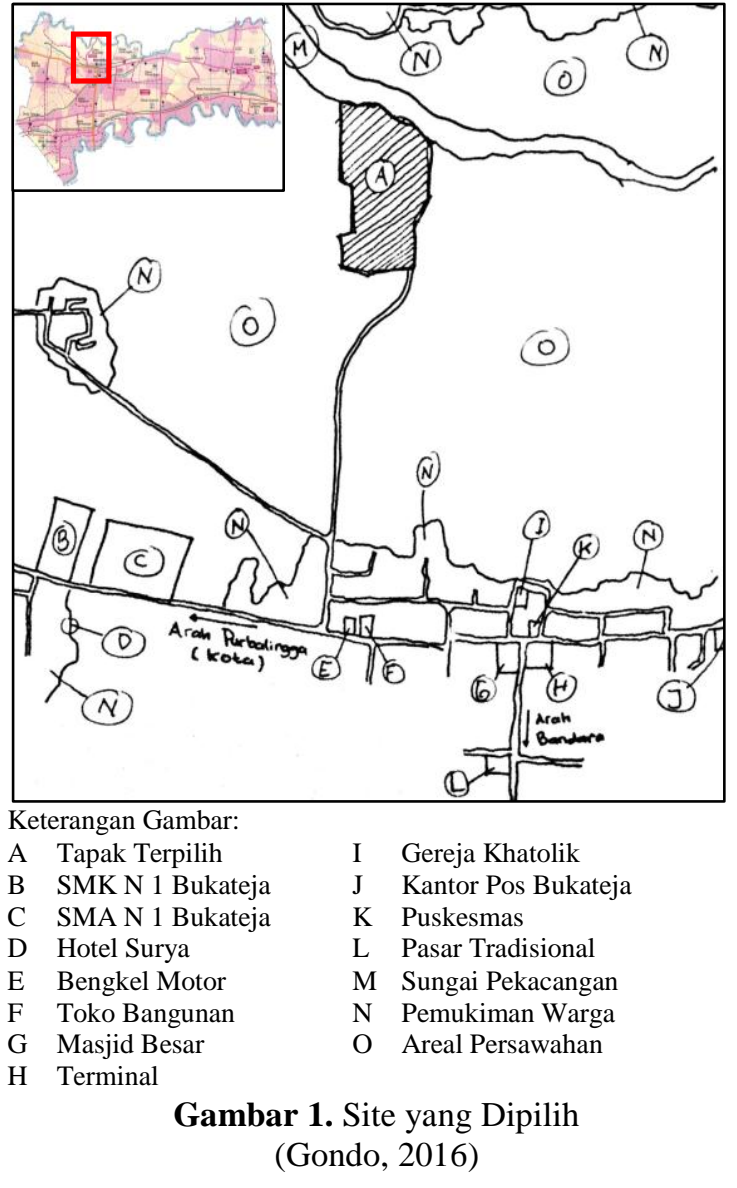

\subsection{Potensi Site}

1. Bukateja memiliki curah hujan tertinggi dibandingkan kecamatan lainnya dari tahun ke tahun, sehingga berpengaruh pada produksi panen yang melimpah dan melebihi rata-rata produksi panen di Kabupaten Purbalingga sendiri (Statistik Daerah Kab. Purbalingga, 2015).

2. Jenis Tanah yang ada di Kecamatan Bukateja didominasi oleh aluvial coklat tua dan latosol coklat, dimana keduanya merupakan jenis tanah yang subur dan sesuai untuk diusahaan sebagai pertanian dan perkebunan.

3. Bukateja menempati urutan kedua untuk serapan tenaga kerja perikanan dengan jumlah tenaga kerja antara 1012-1287 jiwa dimana Bukateja juga menempati urutan pertama untuk potensi kolam ikan dengan luas kolam ikan keseluruhan lebih dari 30 Ha (Dinas Peternakan Kab. Purbalingga, 2009).

4. Bukateja memiliki peternakan sapi yang terbesar dibandingkan kecamatan lain dengan jumlah 2400 ekor, dimana
Rembang hanya 250, Karang moncol 300, Karangreja 1100, Karang jambu 300, Bobotsari 600, Kutasari 1400, Mrebet 1450, Bojongsari 1350, Padamara 2150, Kemangkon 400, Kaligondang 500, Pengadegan 250, Kejobong 650, Kalimanah, Purbalingga, Karanganyar, dan Kertanegara tidak memiliki peternakan sapi (Dinas Peternakan Kab. Purbalingga, 2009).

\section{ANALISIS}

Perancangan Sekolah Alam SMK Pertanian dengan Pendekatan Sistem Permakultur ini muncul berdasarkan urgensi atas potensi serta ancaman yang ada di Purbalingga, dan untuk mengatasi permasalahan dan persoalan yang timbul dalam proses desain, digunakan pendekatan permakultur yang dapat mengintegrasikan antara bangunan dengan alam melalui sistem dalam permakultur.

\subsection{Strategi Pendekatan Desain}

Kelima prinsip permakultur akan diaplikasikan kedalam masing-masing permasalahan yang mana masing-masing permasalahan akan menghasilkan satu atau lebih analisis yang akan digunakan dalam proses desain (lihat tabel 3).

Tabel 3. Strategi Pendekatan Desain

\begin{tabular}{|l|c|r|}
\hline \multicolumn{1}{|c}{$\begin{array}{c}\text { Prinsip } \\
\text { Permakultur }\end{array}$ Lakaran } & \multicolumn{1}{c|}{$\begin{array}{c}\text { Analisis } \\
\text { Desain }\end{array}$} \\
\hline $\begin{array}{l}\text { Sumber-sumber } \\
\text { Biologi }\end{array}$ & $\begin{array}{c}\text { Integrasi } \\
\text { Bangunan } \\
\text { dan Alam }\end{array}$ & Zonasi \\
\cline { 1 - 1 } Skala & $\begin{array}{c}\text { Elemen } \\
\text { Arsitektural }\end{array}$ & $\begin{array}{r}\text { Tampilan \& } \\
\text { Material }\end{array}$ \\
\cline { 1 - 1 } Siklus Energi & $\begin{array}{r}\text { Bentuk \& } \\
\text { Gubahan Massa }\end{array}$ \\
\cline { 1 - 1 } Perencanaan Energi & Independen & $\begin{array}{r}\text { Sumber Energi } \\
\text { Sistem Utilitas }\end{array}$ \\
& &
\end{tabular}

(Gondo, 2016)

Lokasi berhubungan (menempatkan setiap unsur yang saling berhubungan agar saling menguntungkan), akan diaplikasikan pada analisis zonasi.

Sumber-sumber biologi (bekerjasama dengan alam melalui penggunaan bahanbahan yang ada di alam), akan diaplikasikan pada analisis tampilan dan struktur.

Skala (menciptakan sistem skala kemanusiaan melalui desain yang sederhana 
dan sesuai), akan diaplikasikan pada bentuk dan gubahan massa.

Siklus energi (dalam sistem alami tidak ada limbah atau polusi, sisa dari suatu proses akan menjadi sumber untuk proses lainnya), akan diaplikasikan pada analisis sistem utilitas, dimana setiap sisa/limbah seperti grey water dan black water akan diolah sehingga dapat dipakai kembali untuk keperluan lainya, dan juga mengolah air hujan dan air sungai supaya dapat dimanfaatkan untuk kebutuhan sehari-hari.

Perencanaan energi (memanfaatkan energi dan sumber-sumber yang ada untuk menghemat energi), akan diaplikasikan pada analisis sumber energi listrik, dimana perencanaan dan perancangan energi listrik akan memanfaatkan energi dan sumbersumber yang ada di sekitar tapak untuk menghemat biaya.

\subsection{Integrasi Bangunan dengan Alam}

\subsubsection{Analisis Zonasi}

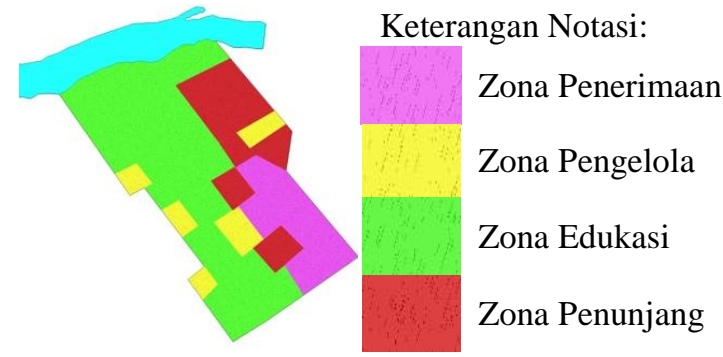

Gambar 2. Analisis Zonasi

(Gondo, 2016)

Digunakan untuk menentukan posisi massa bangunan yang akan dirancang, dimana ruang-ruang yang ada dibagi dalam empat kelompok kegiatan yaitu penerimaan, pengelolaan, edukasi, penunjang (gambar 2). Zonasi ditentukan berdasarkan user, pengelompokkan kegiatan, dan tingkat privasi ruangan yang ada dalam zona tersebut.

Zona penerimaan diletakkan dibagian depan, zona pengelola terpecah pada beberapa titik sesuai kebutuhan, zona edukasi menyebar sesuai dengan tingkat privasi dan pertimbangan lain, dan zona penunjang terpecah sesuai dengan kebutuhan (lihat gambar 3).

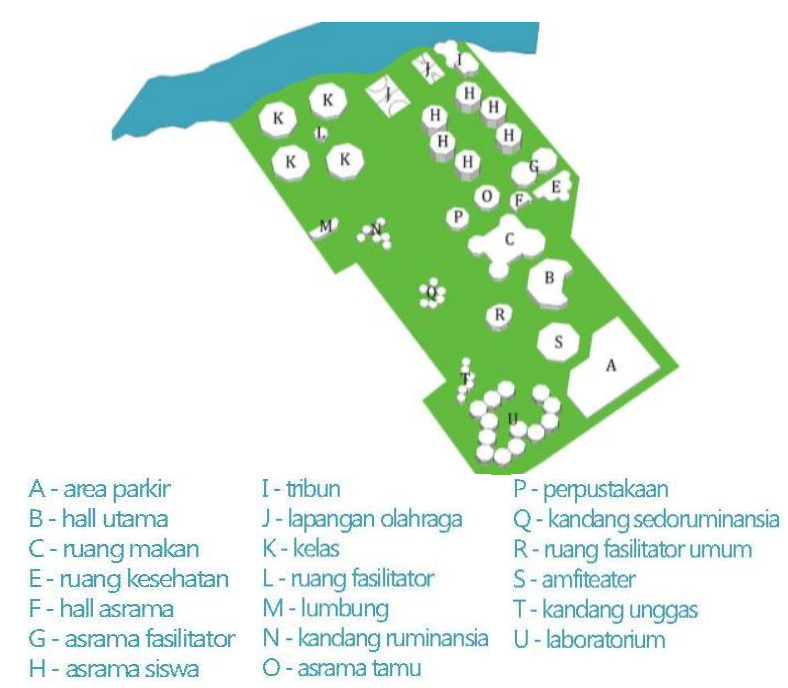

Gambar 3. Analisis Zonasi

(Gondo, 2016)

Analisis zonasi juga digunakan untuk menentukan alur sirkulasi pada kawasan sekolah alam SMK pertanian yang menjadi objek perancangan. Sirkulasi dibagi menjadi tiga yaitu sirkulasi kedatangan, sirkulasi dalam kawasan, dan sirkulasi untuk loading dock. Sirkulasi kedatangan disimbolkan dengan warna putih dan menunjukkan alur sirkulasi dari pintu masuk hingga hall penerimaan. Sirkulasi dalam kawasan disimbolkan dengan warna hitam memiliki pola seperti sebuah pohon yang memiliki banyak dahan dan dari dahan tersebut terbagi lagi menjadi cabang, dimana dahan merupakan alur primer, dan cabang merupakan alur sekunder. Sirkulasi untuk loading dock disimbolkan dengan warna abu-abu menunjukkan alur sirkulasi memutari site supaya kepentingan untuk service tidak menjadi satu dengan jalur pengguna lainnya (lihar gambar 4).

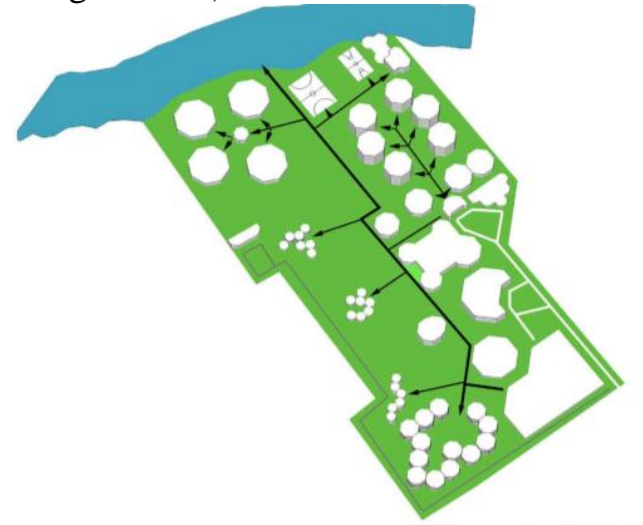

Gambar 4. Alur Sirkulasi (Gondo, 2016) 


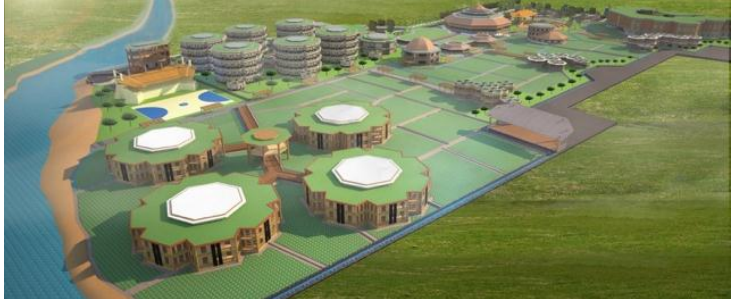

Gambar 5. Perspektif Kawasan (Gondo, 2016)

\subsection{ELEMEN ARSITEKTUR 3.3.1 Analisis Bentuk dan Gubahan} Massa

$0-\square \cdot \square$

\section{$0 \cdot \square+$}
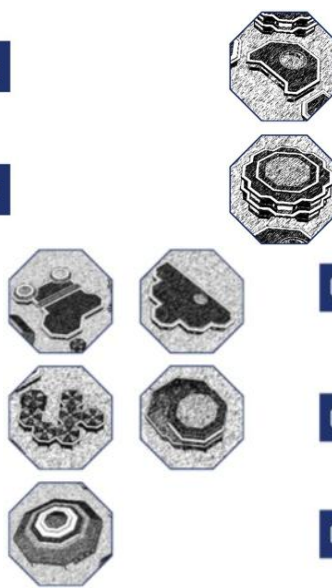

(Gondo, 2016)

Bertujuan memilih konsep bentuk dasar serta gubahannya yang sesuai dengan proses perancangan. Bentuk dasar yang dipilih pada proses perancangan adalah segidelapan yang memiliki sudut tumpul dan banyak sisi sehingga lebih efisien dan sesuai dengan bangunan yang akan dirancang yang menggabungkan antara sekolah alam dengan SMK pertanian. Sedangkan gubahan massa yang dilakukan pada proses perancangan adalah dengan menempelkan dan menyatukan beberapa segidelapan, menggabungkan segidelapan dengan bentuk trapesium dan persegi, serta mengurangi (gambar 6).

\subsubsection{Analisis Tampilan}

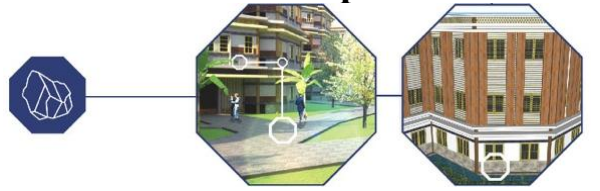

Gambar 7. Analisis Material Batu (Gondo, 2016)
Bertujuan menentukan material yang digunakan dan ekspos pada proses perancangan. Material yang digunakan didalam proses perancangan sekolah alam tingkat SMK dengan pendekatan permakultur di Purbalingga ini berfokus pada penggunaan material-material alam yang juga memiliki nilai lokalitas yang tinggi, yaitu yang ada di Purbalingga dan di area site pada khususnya.

Batu alam diaplikasikan pada dinding, jalan setapak, lantai dalam dan luar bangunan. Bebatuan akan memberikan nuansa dan bahkan membantu menjaga suhu dalam bangunan agar tetap sejuk. Selain itu, batu akan dipakai sebagai material pada dinding bangunan asrama, dengan menggunakan batu, maka akan memberikan rasa aman karena terkesan solid dan kuat (gambar 7).

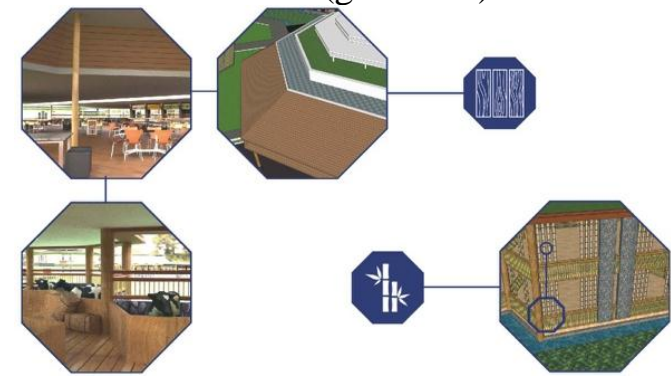

Gambar 8. Analisis Material Kayu \& Bambu (Gondo, 2016)

Bambu akan diaplikasikan untuk berbagai keperluan, selain digunakan sebagai dinding partisi, secondary skin, dan plafon, bambu juga digunakan untuk ornamen pelapis kolom beton(gambar 8).

Kayu akan digunakan untuk finishing dinding dan dinding parsial serta secondary skin pada bangunan seperti laboratorium, kemudian pada lantai dan railing, plafon, serta atap bangunan hall penerimaan, perpustakaan, dan ruang guru (gambar 8).

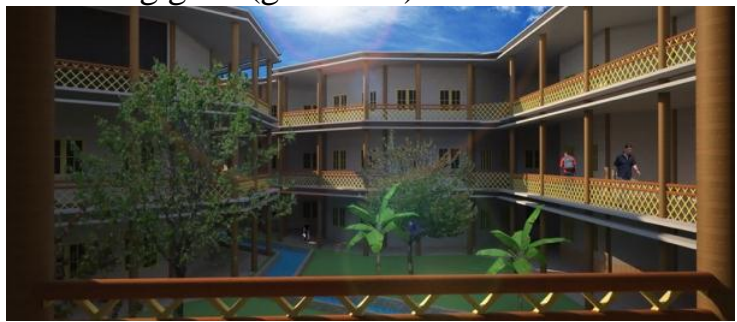

Gambar 9. Pespektif Area Laboratorium (Gondo, 2016) 


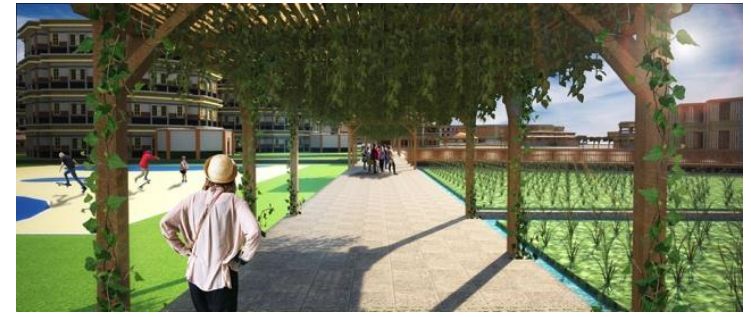

Gambar 10. Perspektif Eksterior (Gondo, 2016)

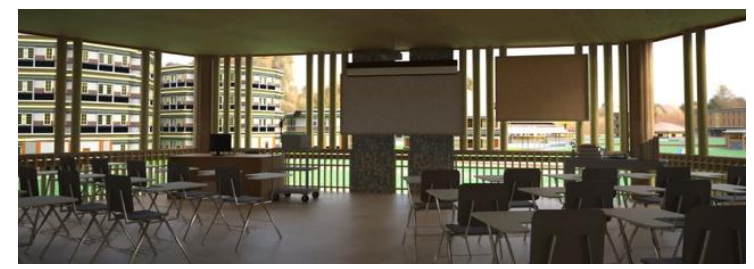

Gambar 11. Perspektif Interior Ruang Kelas (Gondo, 2016)

\subsection{Energi Independen}

\subsubsection{Analisis Sistem Utilitas}

Sistem utilitas dibagi menjadi empat sistem yaitu sistem filtrasi air hujan, sistem pengolahan grey water, sistem pengolahan black water, dan sitem penyulingan air sungai. Sistem-sitem yang ada bertujuan untuk memanfaatkan aliran energi yang ada dialam dan mengolah zat buangan terlebih dahulu sebelum dikembalikan ke alam.

Bangunan yang akan dirancang, direncanakan memiliki tiga lantai dan menggunakan roof garden, sehingga air yang turun akan diterima oleh tanah pada roof garden yang kemudian dialirkan menuju ruang pengolahan air hujan yang tersebar di beberapa tempat yang strategis (gambar 12).

Meski demikian, air hujan dirasa tidak mencukupi kebutuhan, oleh karena itu diperlukan sumber air bersih, selain air hujan. Area site yang dipilih memiliki banyak sumber air, selain sungai besar yang ada di belakang site, air untuk irigasi juga mengalir melalui petak-petak sawah.

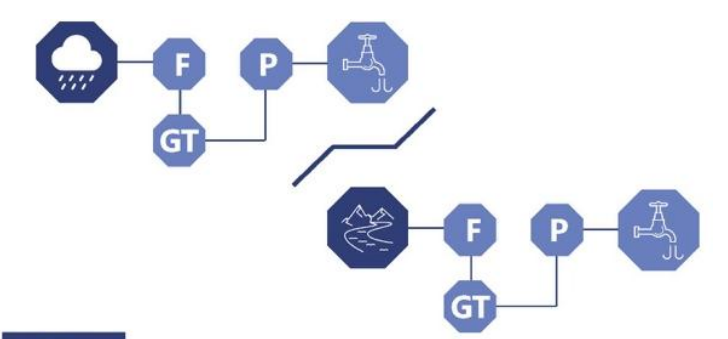

G

Gambar 12. Analisis Pemfilteran Air Hujan dan Penyulingan Air Sungai

(Gondo, 2016)

Air sungai akan dipompa untuk masuk kedalam mesin penyulingan air, dimana air hasil sulingan dapat langsung diminum. Air hasil sulingan juga akan digunakan untuk keperluan mandi, memasak, dan lain-lain (gambar 12).Pemanfaatan air sungai sebagai salah satu sumber air bersih turut menunjang kemandirian sekolah alam yang dirancang, untuk dapat menghasilkan air bersih tanpa bantuan PDAM.

Air kotor yang dimaksud adalah air sisa cucian peralatan memasak, air dari kamar mandi (bukan kloset), dan air dari wastafel. Air kotor ini akan dialirkan terlebih dahulu kedalam sistem pengolahan air (yang terletak di bawah bangunan asrama dan di bawah laboratrium, dimana kegiatan yang menghasilkan air kotor berada. Air kotor akan diproses terlebih dahulu, sebelum nantinya digunakan sebagai air flush toilet/dialirkan ke areal persawahan (gambar 13).

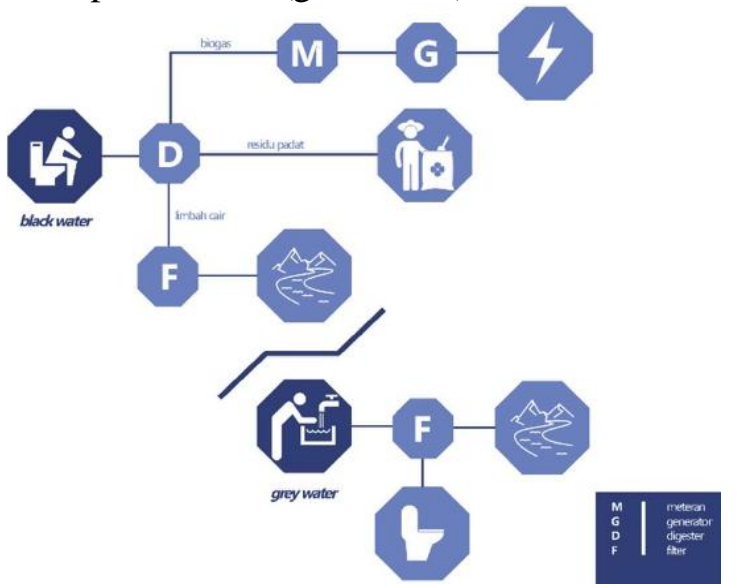

Gambar 13. Analisis Pengolahan Black Water dan Grey Water

(Gondo, 2016)

Black water yang dimaksud adalah limbah yang berasal dari toilet (kloset) dan kandang ternak. Limbah yang berupa kotoran manusia dan ternak ini akan di tampung dalam 
bak penampung, untuk kemudian dimasukkan kedalam tangki digester, dimana produk keluarannya adalah biogas dan limbah padat yang berguna sebagai pupuk yang sangat subur (Rumah OLI, 2015).

Pengolahan black water ini tidak hanya terpusat pada satu tempat saja, tetapi akan di letakkan di beberapa titik, sesuai dengan posisi toilet dan kandang yang menjadi sumber dayanya. Biogas yang dihasilkan dari proses pengolahan black water ini akan digunakan untuk menyokong kebutuhan listrik sekolah alam (gambar 13), sedangkan limbah hasil proses pengolahan ini akan ditampung dan digunakan sebagai pupuk.

\subsubsection{Analisis Sumber Energi Listrik}

Bertujuan untuk menentukan sumbersumber energi yang akan digunakan dalam proses perancangan. Sumber energi listrik dibagi menjadi tiga yaitu menggunakan biogas, panel surya, dan kincir air.

Total daya keseluruhan yang dibutuhkan oleh sekolah alam tingkat SMK dengan pendekatan permakultur di Purbalingga adalah $664526.88 \mathrm{~W}$ dibulatkan menjadi $664.5 \mathrm{~kW}$.

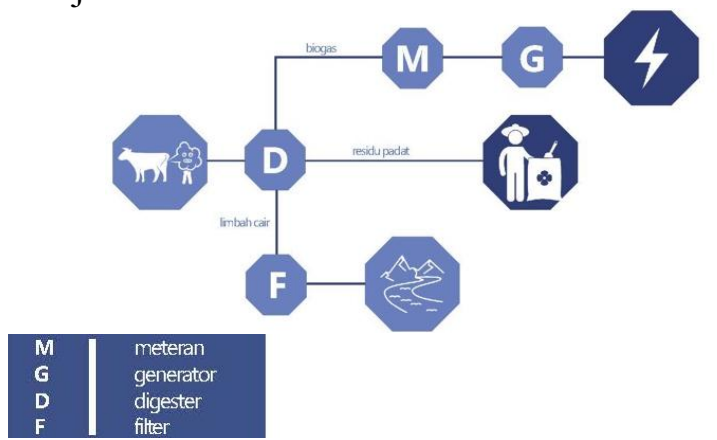

Gambar 14. Pengolahan Biogas

(Gondo, 2016)

Penggunaan sumber energi biogas didasarkan pada pemanfaatan kotoran ternak dan manusia yang biasanya hanya di alirkan kedalam septic tank padahal dapat dimanfaatkan untuk berbagai keperluan.

Tabel 4. Perhitungan Biogas yang Dihasilkan

\begin{tabular}{|c|c|c|c|c|}
\hline Spesies & $\begin{array}{c}\text { Jml/ } \\
\text { ekor }\end{array}$ & $\begin{array}{c}\text { Total } \\
\text { Kotoran } \\
(\mathrm{kg} / \mathrm{hari})\end{array}$ & $\begin{array}{c}\text { Kandungan } \\
\text { Bk Total } \\
(\mathrm{Kg} . \mathrm{Bk})\end{array}$ & $\begin{array}{l}\text { Biogas yang } \\
\text { Dihasilkan } \\
\left(\mathrm{m}^{3} / \mathrm{hari}\right)\end{array}$ \\
\hline Manusia & 866 & $\begin{array}{l}866 \times \\
1.25= \\
1083\end{array}$ & $\begin{array}{l}1083 \times 23 \% \\
=250\end{array}$ & $\begin{array}{l}250 \times 0.03 \\
=7.5\end{array}$ \\
\hline Sapi & 36 & $\begin{array}{l}36 \times 30= \\
1080\end{array}$ & $\begin{array}{l}1080 \times 20 \% \\
=216\end{array}$ & $\begin{array}{l}216 \times 0.04 \\
=8.7\end{array}$ \\
\hline
\end{tabular}

\begin{tabular}{|c|l|l|l|l|}
\hline Kambing & 36 & $\begin{array}{l}36 \times 1.13 \\
=40.68\end{array}$ & $\begin{array}{l}40.68 \times \\
26 \%=10.6\end{array}$ & $\begin{array}{l}10.6 \times 0.05 \\
=0.53\end{array}$ \\
\hline Babi & 36 & $\begin{array}{l}36 \times 7= \\
252\end{array}$ & $\begin{array}{l}252 \times 9 \%= \\
22.68\end{array}$ & $\begin{array}{l}22.68 \times \\
0.06=1.4\end{array}$ \\
\hline Ayam & 180 & $\begin{array}{l}180 \times \\
0.18= \\
32.4\end{array}$ & $\begin{array}{l}32.4 \times 28 \% \\
=9\end{array}$ & $\begin{array}{l}9 \times 0.11= \\
0.99\end{array}$ \\
\hline Itik & 180 & $\begin{array}{l}180 \times \\
0.34= \\
61.2\end{array}$ & $\begin{array}{l}61.2 \times 38 \% \\
=23.26\end{array}$ & $\begin{array}{l}23.26 \times \\
0.11=2.6\end{array}$ \\
\hline
\end{tabular}

(Gondo, 2016)

Berdasarkan analisis perhitungan biogas berdasarkan kotoran yang dihasilkan perhari (tabel 4), maka total biogas yang didapat perhari adalah $7.5+8.7+0.53+1.4+$ $0.99+2.6=21.72 \mathbf{m}^{3} /$ hari. Menurut Departemen Pertanian, setiap satu $\mathrm{m}^{3}$ biogas dapat dikonversikan menjadi $4.7 \mathrm{~kW}$ energi listrik, maka energi listrik yang didapat dari hasil konversi biogas di sekolah alam adalah $102.084 \mathrm{~kW}$.

Daya listrik yang harus dipenuhi panel surya dan kincir air adalah sebesar $562.42 \mathrm{~kW}$, dimana jumlah tersebut dibagi menjadi dua, sehingga daya listrik yang harus dipenuhi oleh panel surya adalah $281.21 \mathrm{~kW}$.

Untuk memenuhi kebutuhan listrik di sekolah alam, diperlukan 279 buah panel surya dan 256 buah baterai.

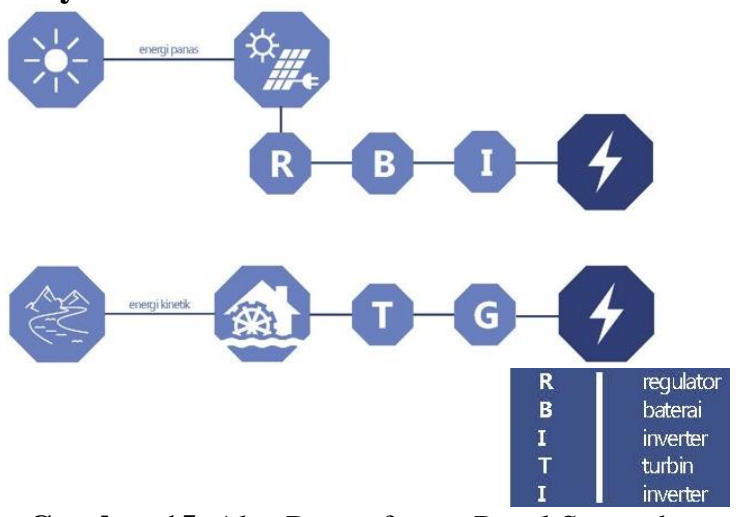

Gambar 15. Alur Pemanfaatan Panel Surya dan Kincir Air

(Gondo, 2016)

Energi yang dapat dihasilkan oleh satu kincir air adalah $38.572 \mathrm{~kW}$, selanjutnya dapat ditemukan berapa kincir air yang dibutuhkan, yaitu $281.21: 38.572=7.29$ buah, dibulatkan menjadi 8 buah kincir air.

Dengan mengaplikasikan pengadaan energi independen, maka sekolah alam yang dirancang dapat menjadi bangunan yang mandiri, dimana PLN hanya digunakan pada kondisi keterbatasan tertentu sebagai sumber 
energi cadangan.

\section{KESIMPULAN}

Sekolah Alam SMK Pertanian dengan pendekatan Permakultur ini terintegrasi dengan kawasan pertanian, peternakan, dan perikanan yang ada disekitarnya, dan ramah lingkungan, serta dapat menjadi wadah pembelajaran yang kondusif bagi siswa setingkat SMK dengan disiplin ilmu pertanian yang menggunakan metode belajar di alam secara langsung, yang mana dalam hal ini berupa kawasan pertanian, peternakan, dan perikanan. Bangunan juga dapat menghidupi dirinya sendiri dengan sumber energi independen yaitu mampu menyediakan persediaan air bersih serta energi listrik secara mandiri.

\section{REFERENSI}

Armstrong, Thomas. 2006. The Best School : How Human Development Research Should Inform Educational Practice. Amerika : Association for Supervision and Curriculum Development.

BPS Kabupaten Purbalingga. 2015. Purbalingga Dalam Angka 2015. https://purbalinggakab.bps.go.id/website/ pdf/Purbalingga-Dalam-Angka-2015.pdf, 6 Juni 2016.

Frick, Heinz dan Hesti, Tri. 2006. Arsitektur Ekologis. Yogyakarta: Kanisius

Green School Bali Indonesia,. 2015. High School Curriculum Book 2015-2016. blog.greenschool.org/wp-content/.../HighSchool-Curriculum-Book-2015-2016.pdf, 10 Juni 2016.

Maryati. 2007. Sekolah Alam, Alternatif Pendidikan Sains yang Membebaskan dan Menyenangkan. Jurdik Kimia FMIPA UNY.

http://staff.uny.ac.id/sites/default/files/132 258076/Sekolah\%20Alam,2007.pdf, 22 Mei 2016.

McKenzie, Lachlan dkk. 2006. A Resource Book for Permaculture: Solutions for Sustainable Lifestyles. Bali: IDEP Foundation.

Mintaraga, Paulus dan Kusumaningdyah N.H. 2014. Satu Proses Merajut Asa Dari Yang Sisa- Belajar Dari Alam Dan Ibu Bumi. Jurnal Sustainable Culture Architecture and Nature Universitas Atma Jaya Yogyakarta.

http://e-

journal.uajy.ac.id/6239/1/Abstraksi\%20S

CAN\%235\%202014.pdf, 3 April 2017.

Mollison, Bill dan Holmgren, David. 1978. Permaculture One: A Perennial Agricultural System for Human Settlements. Amerika : International Tree Crops Institute.

Potensi Peternakan dan Perikanan Kabupaten Purbalingga. 2009. Dinas Peternakan Kabupaten Purbalingga.

Statistik Kecamatan Bukateja. 2015. Kecamatan Bukateja Dalam Angka 2015. https://purbalinggakab.bps.go.id, $\quad 12$ Agustus 2016

Virrayani, Alifia Nurrizky dkk. 2014. Perancangan Sekolah Alam di Kecamatan Kenjeran, Surabaya. Jurnal Sains and Seni Pomits, Vol. 2, No. 1, digilib.its.ac.id/public/ITSpaper-39255-3210100002-paper.pdf, 22 Mei 2016.

datapokok.ditpsmk.net, diakses pada 23Mei 2016 pukul 03.44 WIB

kotaperwira.com, diakses pada Minggu, 22 Mei 2016 Pukul 16.14 WIB

satelitnews.co, diakses pada 24 November 2016 pukul 05.39 WIB

http://www.anneahira.com/tanah-latosol.htm, diakses pada 10/01/17 pukul 13.58 WIB

http://www.facebook.com/Ocean-of-LifeIndonesia, diakses pada 16/05/2016 pukul. 05.18 WIB

http://www.kelair.bppt.go.id/Sitpa/Artikel/Aku a/akua.html diakses pada 15/12/16 pkl 06.50 WIB

http://www.majalahasri.com/arsitektur-hijaudi-green-school-bali/ diakses pada Rabu 01/06/2016 pkl 11.07 WIB 